Available online on 15.09.2020 at http://jddtonline.info
Open Access to Pharmaceutical and Medical Research
(C) 2011-18, publisher and licensee JDDT, This is an Open Access article which permits
unrestricted non-commercial use, provided the original work is properly cited

Open $\odot$ Access

Research Article

\title{
Phytochemical study and antimicrobial activity of Algerian Marrubium vulgare leaf and stem extracts
}

\author{
Nadia BENZIDANE, Ridha SMAHI, Boudjemaa ZABOUCHE, Abdelhalim MAKROUF and Lekhmici ARRAR* \\ Laboratory of Applied Biochemistry, Faculty of Nature and Life Sciences, Ferhat Abbas University of Setif, 19000, Algeria
}

\begin{abstract}
Marrubium vulgare is used worldwide as a source of food flavor and for medicinal purposes. The aim of this study is to investigate polyphenol and flavonoid contents of M. vulgare extracts and their antimicrobial activities. Extraction was conducted using methanol and hexane. The determination of polyphenol content was realized with folin ciocalteu method and flavonoids using $\mathrm{AlCl}_{3}$. Rouph characterization of these compounds was done with HPLC method. Activity against bacteria and fungi was also studied. Results showed that methanolic extracts of leaves (LME) and stems SME) contain relatively high levels of polyphenols ad flavonoids. Except for hexane extract, all extr acts from leaves and stems possess antibacterial and antifungal effects especially against Staphyloccocus aureus and Candida albicans. This finding suggests that M. vulgare methanolic extracts could serve as a basic material for the preparation of antimicrobial drugs.
\end{abstract}

Keywords: Marrubium vulgare, polyphenols, flavonoids, antibacterial, antifungal activities.

Article Info: Received 06 August 2020; Review Completed 17 August 2020; Accepted 24 August 2020; Available online 15 Sep 2020

Cite this article as:

Benzidane N, Smahi R, Zabouche B, Makrouf A, Arrar L, Phytochemical study and antimicrobial activity of Algerian Marrubium vulgare leaf and stem extracts, Journal of Drug Delivery and Therapeutics. 2020; 10(5) :70-74

http://dx.doi.org/10.22270/jddt.v10i5.4353

[1] *Address for Correspondence:

Lekhmici ARRAR, Laboratory of Applied Biochemistry, Faculty of Nature and Life Sciences, Ferhat Abbas University of Setif, 19000, Algeria

\section{INTRODUCTION}

Marrubium vulgare $\mathrm{L}$ is a variety of perennial plant from the labiatae family, known as "horehound" in Europe, "Marrubia" in Tunisia ${ }^{1}$ and Marriwet in Algeria ${ }^{2}$. Marrubium vulgare is cultivated worldwide as a source of food flavor and for medicinal purposes ${ }^{3}$. Several active compounds were isolated from Marrubium vulgare including marrubiin, Premarrubiin $^{5}$, Marrubenol 6 , 11-oxomarrubiin ${ }^{5}$, Marrubiol ${ }^{7}$, Vulgarol $^{8}$, Sclareol ${ }^{9}$, Peregrinin ${ }^{10}, 12(\mathrm{~S})$-hydroxymarrubiin ${ }^{5}$ and 3-deoxo-15-methoxyvelutine $\mathrm{C}^{10}$. These metabolites including diterpenes, sesquiterpenes, flavonoids, and phenylpropanoids were identified from different parts of $M$. vulgare ${ }^{11 .}$

M. vulgare is traditionally used for acute and chronic bronchitis, respiratory disorders, tuberculosis, asthma, skin damage and ulcers. M. vulgare juice and infusion used as a gastric secretion stimulant due to the presence of bitter ingredients particularly marrubinic acid as a choleretic agent. Leaves paste is applied for boils and rheumatism ${ }^{11}$. Dried herb's infusion is used for debility and in high blood pressure. Leaves, flowers, and stem infusion are used as a stomachic for diabetes and in cardiac problems ${ }^{12}$. In Mexico and Germany, it is used in traditional medicine to aid digestion and to treat stomach diseases and diabetes ${ }^{13,14}$. In Brazil, it is employed against gastrointestinal disorders and inflammation 15 . Some of folk uses are confirmed by modern investigations. In fact, the plant is reported to possess antihypertensive ${ }^{16}$, vasorelaxant ${ }^{17}$, hepatoprotective ${ }^{18}$ and antibacterial ${ }^{19}$ properties. We have previously demonstrated that $M$. vulgare extracts exhibit antioxidant activities by their ability to scavenge free radicals, inhibit lipid peroxidation and chelate metals ${ }^{20}$. Furthermore, our results indicate that this plant has powerful effects in the inhibition of the release of inflammatory mediators anti-inflammatory cytokines such as TNF-a, IL-1 $\beta$ and IL-8.

The present study aims to determine the total phenolic and flavonoid contents of various extracts from leaves and stems of Marrubium vulgare from Bejaia region (north Algeria), and to evaluate their antimicrobial capacity.

\section{MATERIAL AND METHODS}

\section{Plant collection}

Marrubium vulgare was harvested in March 2019, in the region of Kherrata, Bejaia, north Algeria and authenticated by Prof. Sabah Charmat from the Faculty of Nature and Life Sciences, Ferhat Abbas University, Setif 1. The stems and leaves were cleaned and left to dry in a dry, ventilated place in the dark. They are then ground into a powder in a blender, and then stored in glass jars protected from light. 


\section{Preparation of extracts}

Powder from the leaves or stems from Marrubium vulgare were mixed with methanol $80 \%(\mathrm{v} / \mathrm{v}) 21$, with magnetic stirring at $60^{\circ} \mathrm{C}$ for $3 \mathrm{~h}$. The mixture was left to macerate for 24 hours in the dark and then filtered. The maceration is renewed, the macerate recovered. The various filtrates are combined and subjected to evaporation under reduced pressure at $40^{\circ} \mathrm{C}$ using a rotavapor Buchi (Germany). After evaporation, the filtrate is dried to give the leave methanolic (LME) or stems methanolic (SME) extracts. LME is oily and required hexane defatting. The hexane phase is collected to give leave hexane extract (LHE). The aqueous phase was collected, filtered and dried at $40^{\circ} \mathrm{C}$ in the oven to give the delipidated methanolic extract (DLME).

\section{Determination of total polyphenols and flavonoids}

The determination of the total polyphenols in the extracts of Marrubium vulgare (leaves and stems) was carried out according to the method of Folin Ciocalteu 22 . A volume of 200 $\mu \mathrm{l}$ of each extract dissolved in distilled or point-of-range water is added to $1 \mathrm{ml}$ of Folin Ciocalteu's reagent (diluted 10 times in distilled water). After $4 \mathrm{~min}$ of incubation at room temperature, $800 \mu \mathrm{l}$ of $\mathrm{Na}_{2} \mathrm{CO}_{3}$ (7.5\%), also diluted in distilled water, were added to the mixture. The previously shaken set was incubated in the dark for 2 hours. The absorbance was then read at $765 \mathrm{~nm}$ by a UV / visible spectrophotometer. The concentration of total polyphenols for each sample is calculated from the regression equation of a calibration range in aqueous medium (0 to $200 \mu \mathrm{g} / \mathrm{ml}$ ), established with gallic acid under the same operating conditions as the excerpts. Results are expressed in milligrams of gallic acid equivalent per gram of extract (mg GAE / $g$ of extract).

Total flavonoids were quantified by the aluminum trichloride method 21 . One $\mathrm{ml}$ of each sample (prepared in methanol) was added to $1 \mathrm{ml}$ of the $\mathrm{AlCl}_{3}$ solution (2\% in methanol). After 10 minutes of incubation, the absorbance was read at $430 \mathrm{~nm}$. The concentration of flavonoids in the methanolic extract was calculated from the calibration curve established with quercetin ( $0-40 \mu \mathrm{g} / \mathrm{ml}$ in methanol) and expressed in milligrams of quercetin equivalent per gram of extract (mg QE / g Extract)

\section{High performance liquid chromatography}

The extracts were analyzed using high performance liquid chromatography system. Each sample was dissolved in methanol (25 mg/mL) and filtered with a $0.45 \mu \mathrm{m}$ membrane before injection into the HPLC-system. The sample was analyzed on a VP-ODS, C18 column with a dimension $(250 \times 4.6 \mathrm{~mm})$ and a particle diameter equal to 5 $\mu \mathrm{m}$. The mobile phase is composed by water (A) and methanol (B). The elution was performed in isocratic gradient conditions, starting from 40 to $100 \%$ of B in 60 $\mathrm{min}$, followed by a re-equilibration step of $20 \mathrm{~min}$. The flow rate was $1 \mathrm{~mL} / \mathrm{min}$ and the elution was performed at room temperature. The UV detection was fixed at $254,280 \mathrm{~nm}$.

\section{Evaluation of antibacterial and antifungal activity}

One gram (+) and two gram (-) bacteria were used in this study: Staphylococcus aureus (ATCC 25923), Escherichia coli (ATCC 25922) and Pseudomonas aeroginosa (ATCC 27853). These strains were provided by the Microbiology Laboratory of the University Hospital Centre (CHU) of Setif, Algeria. The test of the bacteria sensitivity to different extracts was carried out in vitro using the agar medium diffusion method $^{22}$. The bacterial strains were sub-cultured by the streak method on Mueller Hinton agar, and then incubated in an oven at $37^{\circ} \mathrm{C}$ for 18 to 24 hours. From these young cultures, pure colonies were isolated to prepare the bacterial inoculum. Each colony was suspended in $2.5 \mathrm{ml}$ of sterile distilled water. The turbidity of the suspension was measured using a densitometer and adjusted to $0.5 \mathrm{Mac}$ Farland. Sterile $6 \mathrm{~mm}$ diameter Wattman paper discs were impregnated with $10 \mu \mathrm{l}$ of extract and the negative control discs are impregnated with methanol. Discs were gently placed on the agar medium seeded beforehand with a bacterial suspension. Standard Gentamicin discs (10 mg) were used as positive controls. After incubation at $37^{\circ} \mathrm{C}$ for 18 to 24 hours, the diameters of the clear zones of inhibition around the discs were measured. The inhibition zone (s) were recorded and the activity index (AI) was calculated by comparison with respective compounds $(\mathrm{AI}=$ Inhibition zone of test sample/Inhibition zone of the standard).

Fungal strain Candida albicans is provided by the Parasitology Laboratory of the CHU Setif. The antifungal activity was determined by the Sabouraud agar diffusion method containing. The inoculum is prepared from young cultures 2 to 3 days old. A pure colony was suspended in sterile distilled water. The turbidity of this suspension is adjusted to $0.5 \mathrm{Mac}$ Farland (108 CFU / $\mathrm{ml}$ ) and an aliquot of $0.1 \mathrm{ml}$ thereof was spread on the agar. Sterile Wattman paper discs of $6 \mathrm{~mm}$ in diameter, impregnated with $10 \mu \mathrm{l}$ of extract were aseptically deposited on the agar medium. The discs impregnated with DMSO and Fluconale (10 $\mathrm{mg} / \mathrm{ml})$ were used as negative and positive controls, respectively.

\section{Statistical analysis}

Data were analyzed by means of one way Anova to determine statistically significant variance between the groups for each plant extract. Values which showed statistically significant effects were further analyzed and means were compared using Tukey's test. Differences were considered significant at a $\mathrm{P}$ value of less than 0.05 .

\section{RESULTS AND DISCUSSION}

\section{Polyphenol and flavonoid contents}

Yields of extraction and the amounts of polyphenols and flavonoids in different extracts of Marrubium vulgare are presented on table 1 . These results are concordant with those of M. vulgare harvested from Bordj Bouariridj region ${ }^{20}$ except for the flavonoid content of stems extract which is higher (11.72 versus $5.21 \mathrm{mg} \mathrm{QE/g).}$

Table 1: Yields and contents of polyphenols and flavonoids in the Marrubium vulgare methanolic and hexane extracts.

\begin{tabular}{cccc}
\hline Extracts & Yield (\%) & $\begin{array}{c}\text { Polyphenols (mg } \\
\text { GAE/ g) }\end{array}$ & Flavonoids (mg QE/g) \\
\hline LME & $13.27 \%$ & $60.94 \pm 0.07$ & $14.41 \pm 0.15$ \\
DLME & $12 \%$ & $62.95 \pm 0.09$ & $8.06 \pm 0.17$ \\
LHE & $3.77 \%$ & $49.34 \pm 0.06$ & $9.89 \pm 0.06$ \\
SME & $6.7 \%$ & $49.46 \pm 0.03$ & $11.72 \pm 0.07$ \\
\hline
\end{tabular}


It was aimed in this work to identify some of the phenolic compounds present in the methanolic extracts of M. vulgare using HPLC which is a high-resolution chromatographic technique probably the most widely used analytical technique for characterizing the polyphenolic compound ${ }^{23}$.
HPLC analysis of polyphenols (Figure 1) showed that LME contains tannic acid, caffeine and ferulic acid, but when defatted gallic acid was also detected. LHE contains tannic acid, vitamin $\mathrm{C}$ and catechin, whereas in SME only tannic acid and catechin were detected.

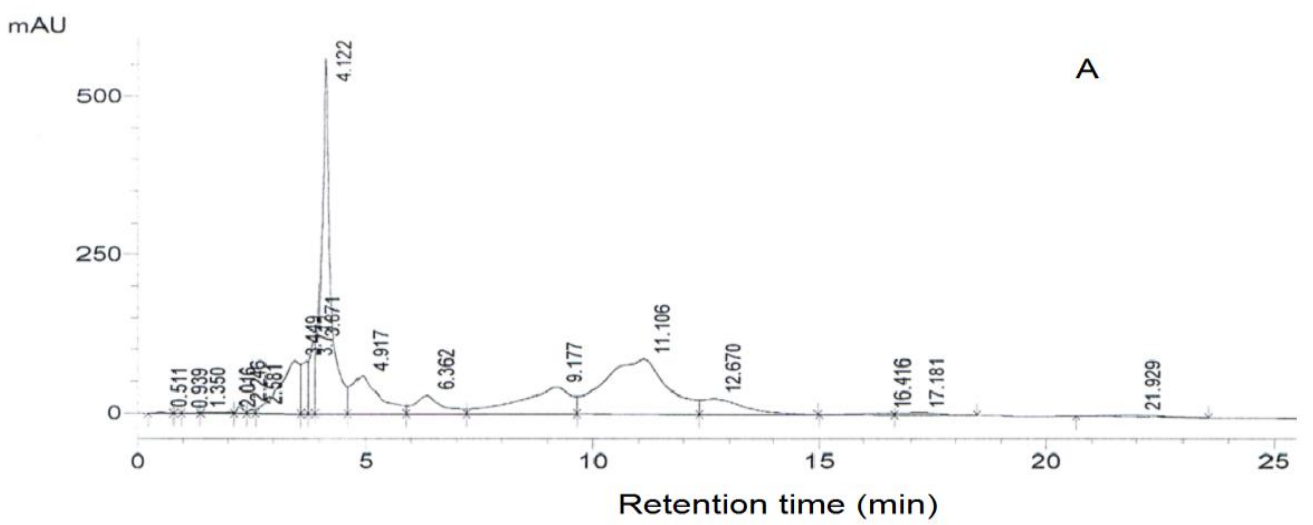

mAU
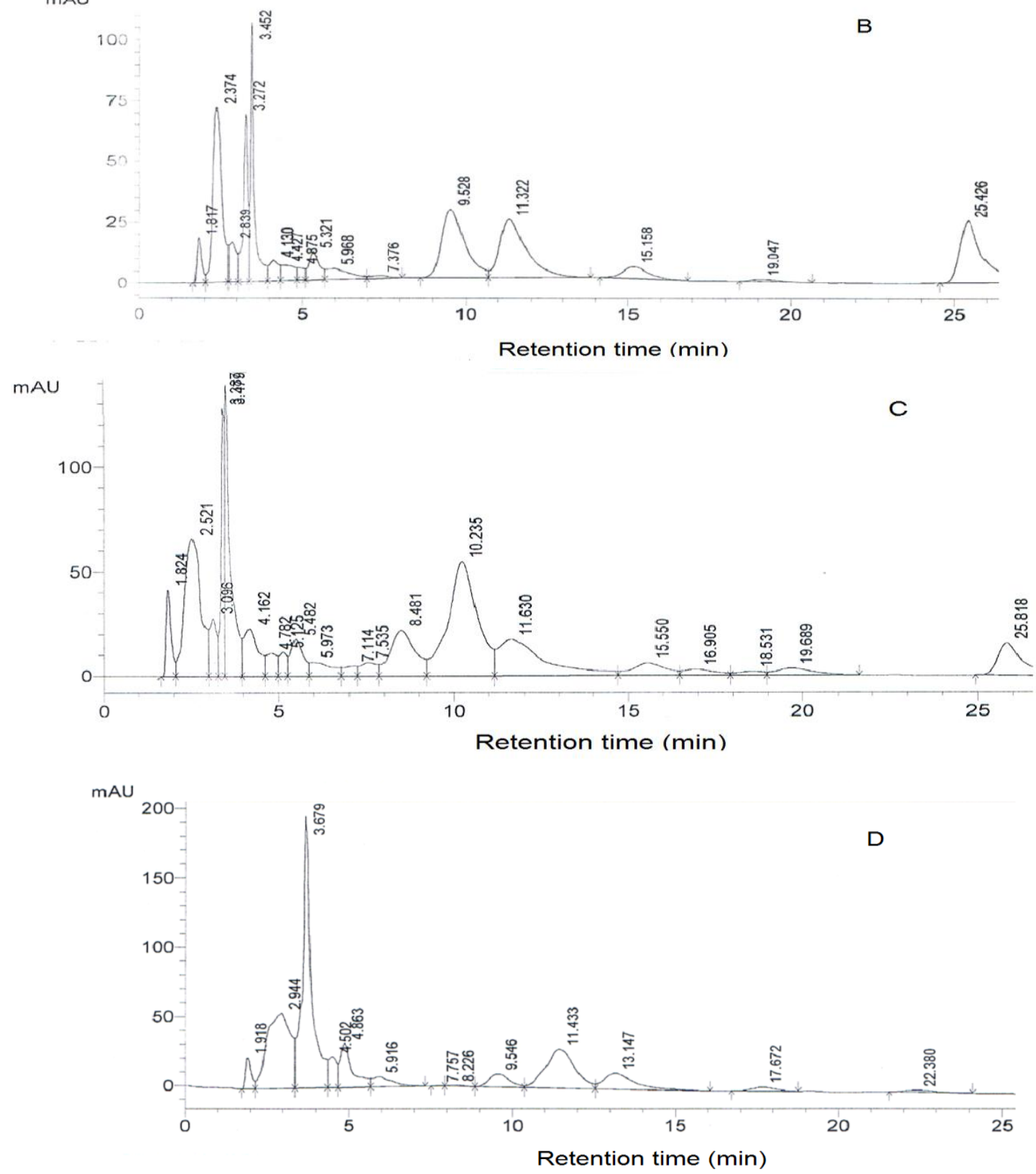

Figure 1: HPLC Chromatograms of Marrubium vulgare extracts. A: leaves methanolic, B: defatted leaves methonolic, C: Leaves Hexane and D: Stem methanolic extracts. 


\section{Antimicrobial activity}

To evaluate the antimicrobial activity of Marrubium vulgare, the activity index (AI) was calculated on the basis of comparison with standard (gentamycin for bacteria and Fluconale for fungi) and extracts (Figure 2).

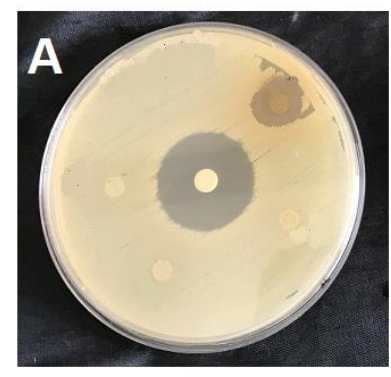

LEAVES

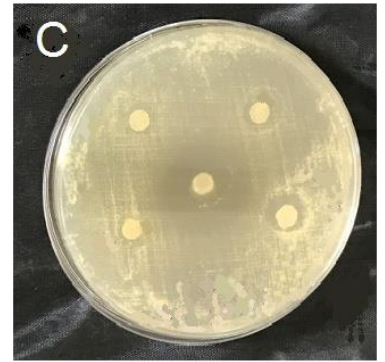

LEAVES

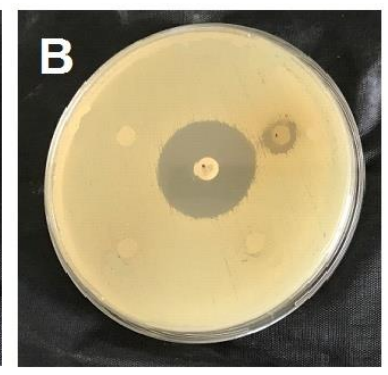

STEM

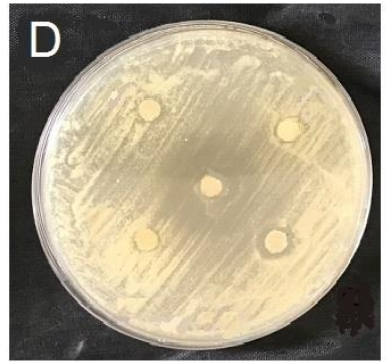

STEM

Figure 2: Inhibition of the growth of Staphyloccocus aureus (A, B) and Candida albicans (C, D) by Marrubium vulgare methanolic extracts using the disc diffusion method.

The results indicated that the methanolic extract of leaves showed higher activity against Staphyloccocus aureus (IZ$11.00 \mathrm{~mm}$; AI-0.53) and Escherichia coli (IZ-7.5 mm; AI-0.33) at the dose of $500 \mathrm{mg} / \mathrm{ml}$ but was less active against Pseudomonas aeruginosa. When defatted with hexane, this methanolic extract showed lower activity (IZ-9.5 mm; AI-
0.41). Stem methanolic extract has good activity against $S$. aureus (IZ-9.0; AI-0.47). In contrast, hexane extract does not have any antibacterial activity (Table 2).

Concerning the antifungal effects against Candida albicans, LME even defatted (DLME) possessed the best activity with IZ-13 \& $10 \mathrm{~mm}$, and AI-0.52 \& 0.45 , respectively (Table 2).

Table 2: Antimicrobial activities of Marrubium vulgare extracts (500 mg/ml). IZ: inhibition zone, AI: Activity index

\begin{tabular}{|c|c|c|c|c|c|c|c|c|}
\hline \multirow{2}{*}{ Extracts } & \multicolumn{2}{|c|}{$\begin{array}{c}\text { Staphylococcus } \\
\text { aureus }\end{array}$} & \multicolumn{2}{|c|}{ Escherichia coli } & \multicolumn{2}{|c|}{$\begin{array}{c}\text { Pseudomonas } \\
\text { aeruginosa }\end{array}$} & \multicolumn{2}{|c|}{ Candida albicans } \\
\hline & IZ & AI & IZ & AI & IZ & AI & IZ & AI \\
\hline LME & $11 \pm 1.5$ & 0.53 & $7.5 \pm 0.5$ & 0.33 & - & - & $13 \pm 1.5$ & 0.52 \\
\hline DLME & $9.5 \pm 0.5$ & 0.41 & - & - & - & - & $10 \pm 1.5$ & 0.45 \\
\hline LHE & - & - & - & - & - & - & - & - \\
\hline SME & $9 \pm 1.5$ & 0.47 & - & - & - & - & $9 \pm 1.5$ & 0.36 \\
\hline
\end{tabular}

Staphylococcus aureus species is currently one of the major causes of nosocomial infections ${ }^{24}$. Recent studies have shown inhibition zone for S. aureus in the range of 0.0-18.0 $\mathrm{mm}^{25-27}$. Cavanagh \& Wilkinson ${ }^{28}$ and Serban et al. ${ }^{27}$ investigations showed that the antimicrobial properties depend on the composition of the extract and the species of microorganism. Phytochemical analysis of plant extracts indicates that the presence of one or more groups of phytoconstituents like flavonoids, tannins, glycoside, phenols, etc. is responsible for antibacterial activity alone or in combinations ${ }^{29}$.

Candidiasis is more frequent in human immunodeficiency virus (HIV)-infected patients and knowledge about the distribution and antifungal susceptibility of oral Candida species is important for effective management of candidiasis $^{30}$. The prolonged management of oral candidiasis in HIV patients might cause the development of drug resistance candidiasis ${ }^{31}$. 


\section{CONCLUSION}

In conclusion, the studied pathogens were more sensitive to methanolic extracts than to the hexane extract, although the polyphenol and flavonoid contents are close. This finding suggests that some of the active compounds in the methanolic extracts are polar, whereas the hexane extract may have dissolved out nonpolar compounds that possess less antimicrobial activity. By their antimicrobial activity, Marrubium vulgare extracts could serve as a basic material for the preparation of drugs for the treatment of nosocomial infections and candidiasis.

\section{ACKNOWLEDGEMENTS}

The authors acknowledge the Algerian Ministry of Higher Education and Scientific Research (MESRS) and the General Directorate of Scientific Research and Technological Development (DGRSDT) for their financial support.

\section{REFERENCES}

[1]. Boukef MK. Traditional medicine and pharmacopoeia, plants of traditional Tunisian medicine (in French), Agence de Coopération Culturelle et Technique. Paris. 1986; pp.163-164.

[2]. Boudjelal A, Henchiri C, Siracusa L, Sari M, Ruberto G. Compositional analysis and in vivo anti-diabetic activity of wild Algerian Marrubium vulgare L. infusion. Fitoterapia. 2012; 83:286-292.

[3]. Abadi A, Hassani A. Chemical composition and antibacterial activity of essential oil of marrubium vulgare from eastern Algeria. International Letters of Chemistry, Physics and Astronomy. 2013; 10(1):61-69.

[4]. Popoola OK, Elbagory AM, Ameer F, Hussein AA, Marrubiin. Molecules. 2013; 18:9049-9060.

[5]. Lodhi S, Vadnere GP, Sharma VK, Usman MdR. Marrubium vulgare $\mathrm{L}$. A review on phytochemical and pharmacological aspects. Journal of Intercultural Ethnopharmacology. 2017; 6(4):429-452.

[6]. Hennebelle T, Sahpaz S, Skaltsounis AL, Bailleul F. Phenolic compounds and diterpenoids from Marrubium peregrinum. Biochemical Systematics and Ecology. 2007; 35(9):624-626.

[7]. Popa DP, Pasechnik GS, Anh PT. Marrubiol-a new diterpenoid from Marrubium vulgare. Chem Nat Comp. 1968; 4(6):291293.

[8]. Popa DP, Pasechnik GS. Structure of vulgarol-new diterpenoid from Marrubium vulgare; Chem Nat Compd. 1975; 11:752-756.

[9]. Seo S, Gomi K, Kaku H, Abe H, Seto H, Nakatsu S, Neya M, Kobayashi M, Nakaho K, Ichinose Y, Mitsuhara I, Ohashi Y. Identification of natural diterpenes that inhibit bacterial wilt disease in tobacco, tomato and arabidopsis. Plant Cell Physiol. 2012; 53(8):1432-1444.

[10]. Masoodi M, Ali, Liang S, Yin H, Wang W, Khan IA. Labdane diterpenoids from Marrubium vulgare. Phytochem Letters. 2015; 13:275-279.

[11]. Meyre-Silva C, Cechinel-Filho V. A review of the chemical and pharmacological aspects of the genus marrubium. Curr Pharm Des. 2010; 16:3503-3518.

[12]. Quattrocchi U. CRC World dictionary of medicinal and poisonous plants: common names, scientific names, eponyms, synonyms, and etymology. Boca Raton, FL: CRC Press. 2012; p. 2430.

[13]. Herrera-Arellano A, Aguilar-Santamaria L, Garcia-Hernandez B, Nicasio-Torres P, Tortoriello J. Clinical trial of cecropia obtusifolia and Marrubium vulgare leaf extracts on blood glucose and serum lipids in type 2 diabetics. Phytomed. 2004; 11:561-566.
[14]. Knoss W. Marrubium vulgare (White Horehound): In vitro culture, and the production of diterpene marrubiin and other secondary metabolites. Biotechnol. Agric. For. 1999; 43:274289.

[15]. de Souza, MM, de Jesus RA, Cechinel-Filho, V, Schlemper V. Analgesic profile of hydroalcoholic extract obtained from Marrubium vulgare. Phytomedicine. 1998; 5:103-107.

[16]. El Bardai S, Lyoussi B, Wibo M, Morel N. Comparative study of the antihypertensive activity of Marrubium vulgare and of the dihydropyridine calcium antagonist amlodipine in spontaneously hypertensive rat. Clin Exp Hypertens. 2004; 26:465-474.

[17]. El Bardai S, Morel N, Wibo M, Fabre N, Llabres G, Lyoussi B, Quetin-Leclercq J. The vasorelaxant activity of marrubenol and marrubiin from Marrubium vulgare. Planta Med. 2003; 69(1):75-77.

[18]. Verma A, Masoodi M, Ahmed B () Lead finding from whole plant of Marrubium vulgare $\mathrm{L}$. with hepatoprotective potentials through in silico methods. Asian Pac J Trop Biomed 2012; 2:S1308-S11.

[19]. Masoodi MH, Ahmad B, Zargar IM, Khan SA, Khan S, Singh P. Antibacterial activity of whole plant extract of Marrubium vulgare. Afr J Biotechnol. 2008; 7:86-87.

[20]. Namoune I, Khettal B,Assaf AM, Elhayek S, Arrar L. Antioxidant and anti-inflammatory activities of organic and aqueous extracts of northeast Algerian Marrubium vulgare. Phythérapie. 2018; 16(S1):S119-S129.

[21]. Amraoui N, Mayouf N, Charef N, Baghiani A, Arrar L. Antioxidant, anti-inflammatory and anti-arthritic activities of methanol extract of Tamus communis L. roots. Tropical Journal of Pharmaceutical Research. 2019; 18(7):1499-1506.

[22]. Amamra S, Charef N, Arrar L, Belhaddad O, Khennouf S, Zaim $\mathrm{K}$, Baghiani A. Phenolic content, antioxidant and antibacterial effects of fruit extracts of Algerian ash, Fraxinus excelsior. Indian Journal of Pharmaceutical Sciences. 2018; 80(6):10211028.

[23]. Gómez-Caravaca AM, Gómez-Romero M, Arráez-Román D, Segura Carretero A, Fernández-Gutiérrez A. Advances in the analysis of phenolic compounds in products derived from bees. J. Pharmaceut. Biomed. Anal. 2006; 41:1220-1234.

[24]. Exner M. Divergent opinions on surface disinfection: myths or prevention? A review of the literature. GMS Krankenhaushygiene Interdisziplinar. 2007; 2:1-7.

[25]. Dorman H.J.D., Deans S.G.: Antimicrobial agents from plants: Antibacterial activity of plant volatile oils. J Appl Microbiol. 2000; 88:308-316.

[26]. Ghardi TA, Mousavi SL, Sharafi SM, Alipour Astaneh SD, Rezaee MB. Antimicrobial, antioxidant, hematologic and cytotoxic properties of Lavandula angustifolia essential oil. Modares J Med Sci. 2010; 12:54-58.

[27]. Serban E.S., Ionescu M, Matinca D, Maier CS, Bojita MT. Screening of the antibacterial and antifungal activity of eight volatile essential oils. Farmacia. 2011; 59:440-446.

[28]. Cavanagh MMA, Wilkinson JM. Biological activity of Lavender essential oil. Phytother Res. 2002; 16:301-308.

[29]. Ahmad I, Aqil, F. In vitro efficacy of bioactive extracts of 15 medicinal plants against ESbL-producing multidrug-resistant enteric bacteria. Microbiolog. Res. 2007; 162:264-275.

[30]. Mohamed H, Krema Z, Mokthar E, Ellabib M, El Magrahi H, Eshwika A. Oral Candida colonization in HIV-infected patients: Species and antifungal susceptibility in Tripoli/Libya. Int J Clinical Microbiol Biochem Technol. 2018; 1-8.

[31]. Martins MD, Lozano-Chiu M, Rex JH. Point prevalence of oropharyngeal colonization of fluconazole-resistant Candida in human immunodeficiency virus-infected patients. Clin Infect Dis. 1997; 25:843-846. 